\title{
Independent risk factors for failure of non-operative management in patients with splenic injury
}

\author{
Zubeyir Bozdag ${ }^{1 *}$, Abdullah Boyuk ${ }^{1}$, Ahmet Turkoglu $^{1}$, Taner Ciftci $^{2}$, Omer Uslukaya ${ }^{1}$, \\ Abdullah Oguz ${ }^{1}$, Metehan Gumus ${ }^{1}$
}

\section{Abstract}

Objective: It is crucial to assess non-operative management (NOM) of risk failures before it is preferred as a management option for treatment of splenic trauma or rupture. The purpose of this study is to investigate the outcome of non-operative management of splenic trauma, and to determine the independent predictive factors effecting NOM failure.

Material and Methods: Seventy-seven patients among all of consecutive patients admitted with splenic trauma between January 2005 and June 2015 were included in the study. The patients were divided into two groups. Group 1: Successfully treated with non-operative management, and Group 2: The failure of non-operative management. Data recorded included patient demographics, vital signs, injury mechanism, Injury Severity Score (ISS), splenic trauma grade, hematologic parameters, Glasgow Coma Scale (GCS), transfusion requirements, and length of hospital stay.

Results: There were $66(85.7 \%)$ patients in group 1, while only 11 patients (14.3\%) in group 2. Mechanism of injury was blunt in seventy-one patients and, penetrating in 6 patients. ISS [Odds Ratio $=1.293 ; 95 \% \mathrm{CI}=1.045$ $1.601 ; \mathrm{p}=0.018$ ] and blood transfusion [Odds Ratio $=2,739 ; 95 \% \mathrm{CI}=1.140-6,581 ; \mathrm{p}=0.024$ ] were detected to be an independent predictive factors for the failure of non-operative management. Group 1 has significantly higher hospitalization period (7.73 \pm 2.867 vs $6.67 \pm 2.289)$.

Conclusions: Non-operative management failure risk is crucial and higher in patients with high ISS and in patients who require much blood transfusion in first 24 hours. Special attention should be paid to these patients if non-operative management becomes the preferred management option.

Key words: Non-Operative Management, NOM, Splenic Rupture, Risk Factors

Introduction

The spleen is one of the most commonly injured organs in abdominal trauma. Historically, the best treatment option for patients with traumatic splenic injury was splenectomy (1). Procedures for preservation of the spleen have attracted more attention since the description sepsis of postsplenectomy by Singer (2).

Developments in the intensive care units and in the field of radiology have provided an opportunity for application of spleen preservation procedures and nonoperative management (NOM). Nowadays, the standard treatment choice of hemodynamically stable patients with blunt splenic trauma is NOM, although it is associated with a potential risk of failure.

The greatest advantage of NOM is the preservation of splenic function.
In many studies, $78-98 \%$ success rates for NOM have been described $(1,2,3,4,5)$. However, many risk factors have been described in the literature that may lead to failure of NOM. Hemodynamic instability, age above 55 years, multiple organ injuries, higher splenic trauma grade, Injury Severity Score (ISS) and transfusion requirement, lower blood pressure and GCS at admission, degree of hemoperitoneum, and contrast extravasation are patient-related factors frequently reported to be associated with failure of $\operatorname{NOM}(1,6)$. However, there is no consensus on the predicting factors that may lead to NOM failure.

In this study, the outcomes of splenic trauma of NOM were retrospectively investigated and determined the independent predictive factors effecting NOM failure.

Received:21-10-2015, Accepted 22-10-2015, Available Online 15-02-2016

1Department of General Surgery, School of Medicine, Dicle University, Diyarbakır, Turkey

2Department of Anestesia and Reanimasyon, School of Medicine, Trakya University, Edirne, Turkey.

*Corresponding Author: Zubeyir Bozdag E-mail: zubeyirbozdag@gmail.com 
Material and Methods

The study was conducted at the Dicle University after approval of study by the ethical committee. A total of 256 patients with splenic trauma had been admitted to our clinic during January 2005 to June 2015. Patients who received NOM treatment and met the following criteria were included in the study; hemodynamically stable, no demonstrable peritoneal irritation finding on physical examination, and no injuries on computed tomography (CT) scans requiring operative intervention. All but unstable patients were evaluated with imaging modalities like ultrasonography (US) and CT. Exclusion criteria are factors like high bleeding risk such as coagulopathy, use of anticoagulants. A total of 77 patients with splenic trauma meeting the above criteria were included in the study.

Records of these patients were retrospectively evaluated. Patient demographics, vital signs, injury mechanism, Injury Severity Score (ISS), splenic trauma grade, hematologic parameters, Glasgow Coma Scale (GCS) score, transfusion requirements, and length of hospital stay were recorded. This data was then compared between two groups which were defined as Group 1; patients were successfully treated with NOM and Group 2; patients requiring operation due to the failure of NOM. Patients were monitored closely in an intensive care unit or monitored setting. Oral intake was restricted, parenteral fluids were given, and bed rest was ordered. Immediate operation were performed when patients exhibited any abnormality requiring operative management like instable hemodynamic condition, continuing bleeding, or positive peritoneal irritation signs. American Association for the Surgery of Trauma (AAST) classification was used for grading splenic trauma (7).

\section{Statistical analysis}

SPSS package program (SPSS for Windows 16.0, SPSS Inc. Chicago, IL) was used for statistical analysis. Chi square or Fischer's exact test was used for comparisons of percentages, while independent $t$ test was used for the mean values. Multivariate regression analysis was used to detect the independent factors effecting failure of NOM of splenic trauma. A $\mathrm{p}<0.05$ was accepted as being statistically significant.

\section{Results}

NOM procedures were followed for a total of 77 patients. However, NOM had failed in 11 patients $(14.3 \%)$, and splenectomy was performed. The clinical finding and patients' demographics are demonstrated in Table 1. Mechanism of injury was blunt in seventy-one patients, and penetration in six in injuries. Mean length of hospital stay was $6.67 \pm 2.289$ for group I, $7.73 \pm 2.867$ for Group II. There were no mortalities.

While patient demographics, vital signs, GCS, number of additional organ injury were not different at a statistically significant level between the groups in a univariate analysis, Splenic trauma grade, ISS, Hg levels, and transfusion requirements were different. So they entered into a multivariate logistic regression analysis. ISS [Odds Ratio (OR) $=1,293$; $95 \%$ Confidence Interval $(\mathrm{CI})=1,045-1,601$; $\mathrm{p}=0.018$ ] and blood transfusion [Odds Ratio $(\mathrm{OR})=$ 2,739; 95\% Confidence Interval (CI) $=1,140-6,581$; $\mathrm{p}=0,024]$ were determined to be independent predictive factors for the failure of NOM (Table 2). Length of hospital stay was significantly higher in Group 1 than in Group $2(6.67 \pm 2.289$ vs $7.73 \pm 2.867)$.

Table 1: Comparison of demographic and clinical characteristics of the patients

\begin{tabular}{|c|c|c|c|}
\hline & Group 1(NOM) $(\mathrm{n}=66)$ & Group $2($ NOM failure $)(n=11)$ & $P$ value \\
\hline Age (years) & $30.86 \pm 11.124$ & $30.91 \pm 14.543$ & 0.484 \\
\hline $\mathrm{SBP}(\mathrm{mmHg})$ & $112.27 \pm 13.103$ & $100.91 \pm 11.362$ & 0.271 \\
\hline ISS & $5.64 \pm 3.728$ & $15.36 \pm 6.652$ & 0.018 \\
\hline GCS & $13.88 \pm 1.504$ & $13.55 \pm 1.508$ & 0.167 \\
\hline \multicolumn{4}{|c|}{ Grade of splenic injury $n(\%)$} \\
\hline I & $20(30.3 \%)$ & 0 & \\
\hline II & $35(53 \%)$ & $1(\% 9)$ & $<0.0001$ \\
\hline III & $7(10.6 \%)$ & $5(45.5 \%)$ & \\
\hline IV & $4(6.1 \%)$ & $5(45.5 \%)$ & \\
\hline $\operatorname{Hgb}(g / d L)$ & $12.58 \pm 1.683$ & $10.21 \pm 1.600$ & 0.699 \\
\hline Blood transfusion (IU)* & $0.62 \pm 1.212$ & $2.82 \pm 0.751$ & 0.024 \\
\hline EAI & $23(34.8 \%)$ & $6(54.5 \%)$ & 0.314 \\
\hline IAI & $27(40.9 \%)$ & $6(54.5 \%)$ & 0.515 \\
\hline LS(days) & $6.67 \pm 2.289$ & $7.73 \pm 2.867$ & 0.001 \\
\hline
\end{tabular}


Table 2: "Binary Logistic Regression" to detect predictors for the failure of non-operative treatment

\begin{tabular}{lccc}
\hline Variables & Odds Ratio & $\begin{array}{c}\text { 95\% Confidence Interval } \\
\text { (Lower-Upper) }\end{array}$ & p Value \\
\hline ISS & 1.293 & $(1.045-1.601)$ & $0.018^{*}$ \\
Grade of splenic injury & 1.042 & $(0.064-17.005)$ & 0.977 \\
SBP(mmHg) & 0.952 & $(0.851-1.065)$ & 0.388 \\
Hgb levels & 0.853 & $(0.381-1.909)$ & 0.699 \\
Blood transfusion & 2.739 & $(1.140-6.581)$ & $0.024^{*}$ \\
\hline
\end{tabular}

ISS: Injury Severity Score SBP: Systolic blood pressure.

*ISS and blood transfusion was significant independent predictive factor for non-operative management.

\section{Discussion}

The NOM of splenic trauma has gained increasing acceptance in adults recently [8]. The benefits of NOM of splenic trauma include the followings: preservation of splenic function, avoidance of overwhelming post-splenectomy sepsis, avoidance of potential postsplenectomy thrombocytosis and avoidance of the risks associated with nontherapeutic laparotomy [9]. It is critically important to predict in which patients NOM will fail. However, the absence of a consensus regarding which patients NOM should be administered requires further study. A positive correlation was founded between the splenic trauma grade and NOM failure in many studies $(1,10,11,12$, $13)$.

217 patients were identified splenic trauma grade of 3 or higher on $\mathrm{CT}$ as an independent predictive factor for failure of NOM by Velmahos et al (14). However, it was reported that trauma grade was not identified as a predictive factor for failure of NOM 815). We found the correlation between splenic trauma grade and NOM failure to be statistically significant but the splenic trauma grade was detected not to be predictive factor for NOM failure our study. We attribute this to the bias we have as we were inclined to administer NOM on lower grades of splenic trauma.

There is no consensus in the literature regarding the relationship between NOM failure rates and the number of blood transfusion requirements. In a study, more than 1 IU of RBC transfused was identified as predictive factor for failure of NOM [14]. Velmahos et al [14] also identified the higher failure rate in patients who were transfused more than $1 \mathrm{IU}$ of RBC. Also, Sartorelli et al. (16) proposed that the failure rate is higher in patients who received more than 4 IU of RBC. Boyuk et al (10) proposed that the failure rate is higher in patients who received more than $2 \mathrm{IU}$ of RBC. Hsieh et al (17) reported that patients with a low hemoglobin level at admission and a high number of transfusion requirement in the intensive care unit were predictive for NOM failure.
In the review of Olthof et al. (1), no evidence was found between hemoglobin/hematocrit levels and predictive factors for NOM failure in patients with blunt splenic trauma. In our study, the rate of NOM failure was higher in patients who required more than 2 IU of RBC in first 24 hours.

NOM is not proper management option in elderly patients, especially 55 years and over $(18,19,20)$. Rodrigeus et al (21), proposed that contraction and retraction of intra-parenchymal vessels are limited due to less elastic splenic capsule with increasing age. Failure of NOM may occur due to restricted splenic distention in the spleens of the elderly (10). In the report of Renzulli et al. (22), where they investigated the factors leading to NOM failure in patients with blunt splenic trauma, age over 40 years was the only independent predictive factor for failure of NOM. Whereas, age was not found to be limiting factors for NOM administration in many other studies $(11,12$, $13,14)$. Similarly, we also found age to not be a factor leading to NOM failure.

In the past, patients with altered mental status were not treated conservatively because of overlooked intra-abdominal injuries that might require laparotomy. According to Pal [24] the CT scans represent a very effective diagnostic method for hemodynamically stable patients with altered mental status. In our study GCS was not different between the two groups. In eight studies, where Systolic Blood Pressure (SBP) was analyzed $(11,14,17,19.24,25$, $26,27)$, only one study determined a correlation between failed NOM and statistically significantly lower SBP in admission (12).

Rosati et al (9) reported patients managed by immediate splenectomy had a significantly lower SBP as compared with those managed by NOM. The proportion of patients who presented with an SBP of $<90$ was also significantly higher in the group managed by immediately splenectomy. There was no difference between SBP of two groups compared in this study. 
In review of Olthof et al. (1), ISS was found to be a strong prognostic factor for failure of NOM in patients with traumatic blunt splenic trauma. ISS was suggested as an independent predictor of failure by Bee et al. (27) and Malhotra et al. (29).

Velmahos et al. (14) observed a higher mean ISS in patients with NOM failure. ISS of greater than 25 was statistically significant in a univariate analysis. However it was not an independent predictive factor in multivariate analysis. It was demonstrated that patients who failed NOM were more likely to have 25 or higher ISS values (1). In the study of Rosati et al (9), patients undergoing immediate splenectomy had a higher ISS as well as higher morbidity and mortality rates compared to patients successfully managed nonoperatively. In our study, ISS was found to be an independent predictive factor for failure of NOM.

Gender is not considered as an important factor for NOM failure in the literature. However, one study determined a higher NOM failure in men (11). Gender was not found to be a predictive factor in our study.

Although NOM approaches have been considered as standard of care in hemodynamically stable patients with blunt splenic trauma for a long time, it is also being increasingly utilized in patients with penetrating abdominal trauma, including the settings of solid organ injury. Despite this evolution of clinical practice in penetrating splenic trauma, safety and efficacy of NOM is not known exactly (26). In addition to blunt trauma, NOM also can be applied for penetrating traumas. Dematriades et al (30) applied it liver in $28.4 \%$ of selected patients, kidney in $14.9 \%$, and spleen in $3.5 \%$. In our study, seventy-one patients who suffered from blunt and, six from low-grade penetrating injuries were treated non-operatively.

Hospitalization in NOM of splenic trauma varies between 3 to 7 days, if no other injuries are present to elicit a prolonged stay (31). NOM failure increased length of hospital stay and increased mortality in selected subsets of patients $(9,32)$. Accordingly, NOM has shorter length of hospital stay than operative management in patients with isolated solid organ injuries (30). In contrast, the length of hospital stay of NOM group was shorter in this study.

There are no comprehensive guidelines for management and follow-up of patients who were planned for NOM in evidence-based setting (33). In the report of Renzulli et al. (22), patients with splenic trauma were admitted to an intermediate care unit the first 24-48 hours. Hemoglobin was measured per four-six hours in the first day and daily after that, and 1-7 days bed rest was recommended. Restrictions on the activities of patients after discharge varied between 4 and 12 weeks based on the grade of splenic trauma and the demand of the activity. Strict bed rest for 48-72 hours and then limited bed rest for one week were recommended by the Renzulli et al (22), and patient's injuries and status depended limitations were prescribed.

\section{Conclusion}

Currently, NOM is the standard treatment for treating hemodynamically stable patients with splenic trauma without additional traumas which require laparotomy. We found the chance of NOM failure to be higher in patients with a higher ISS, and in patients requiring blood transfusion in first 24 hours. Special attention should be paid to these patients when they are treated with NOM approaches. Predicting NOM failure reduces the frequency of non-operative treatment failure, especially in severe splenic trauma; however, it is still necessary to perform prospective, randomized clinical investigations.

Acknowledgments: We are grateful to Dicle University DUBAP for their sponsorship regarding English editing of this manuscript.

Conflict of Interest: The authors declare no potential conflicts of interest with respect to the research, authorship, and/or publication of this article.

\section{References}

1. Olthof DC, Joosse P, van der Vlies CH, de Haan RJ, Goslings JC. Prognostic factors for failure of nonoperative management in adults with blunt splenic trauma: a systematic review. J Trauma Acute Care Surg. 2013;74 :546-57.

2. Singer DB. Post-splenectomy sepsis. Perspect Pediatr Pathol 1973;1: 285-311.

3. Galvan DA, Peitzman AB. Failure of nonoperative management of abdominal solid organ injuries. Curr Opin Crit Care. 2006;12:590-4

4. Watson GA Rosengart MR Zenati MS, et al. Nonoperative management of severe blunt splenic trauma: are we getting better? J Trauma. 2006;61:1113-8; discussion 1118-9.

5. Smith J, Armen S, Cook CH, Martin LC. Blunt splenic trauma: have we watched long enough? J Trauma. 2008;64:656-63. discussion 663-5

6. Tugnoli G, Bianchi E, Biscardi A, et al. Nonoperative management of blunt splenic trauma in adults: there is (still) a long way to go. The results of the BolognaMaggiore Hospital trauma center experience and development of a clinical algorithm. Surg Today. 2014 Dec 5. [Epub ahead of print]

7. Moore EE, Cogbill TH, Jurkovich GJ, Shackford SR, Malangoni MA, Champion HR. Organ injury scaling: spleen and liver (1994 revision). J Trauma. 1995;38:323-4

8. Notash AY, Amoli HA, Nikandish A, Kenari AY, Jahangiri F, Khashayar P. Non-operative management in blunt splenic trauma. Emerg Med J. 2008;25:210-2 
9. Rosati C, Ata A, Siskin GP, Megna D, Bonville DJ, Stain SC. Management of splenic trauma: a single institution's 8 year experience. Am J Surg. 2015;209:308-14. doi: 10.1016/j.amjsurg.2014.06.034. Epub 2014 Oct 7

10. Böyük A, Gümüş $M$, Önder A, et al. Splenic injuries: factors affecting the outcome of non- operative management. European Journal of Trauma and Emergency Surgery. June 2012;38:269-74

11. Gonzalez M, Bucher P, Ris F, Andereggen E, Morel P. Splenic trauma: predictive factors for failure of nonoperative management [in French]. J Chir (Paris) 2008;145:561-7.

12. Jeremitsky E, Kao A, Carlton C, Rodriguez A, Ong A Does splenic embolization and grade of splenic trauma impact nonoperative management in patients sustaining blunt splenic trauma? Am Surg. 2011;77:215-20.

13. Nix JA, Costanza M, Daley BJ, Powell MA, Enderson BL Outcome of the current management of splenic trauma. Trauma. 2001;50:835-42.

14. Velmahos GC, Chan LS, Kamel E, et al. Nonoperative management of splenic trauma: have we gone too far? Arch Surg. 2000;135:674-9.

15. Sharma OP, Oswanski MF, Singer D, Raj SS, Daoud YA. Assessment of nonoperative management of blunt spleen and liver trauma. Am Surg. 2005;71:379-86.

16. Sartorelli KH, Frumiento C, Rogers FB, Osler TM. Nonoperative management of hepatic, splenic, and renal injuries in adults with multiple injuries. $\mathrm{J}$ Trauma. 2000;49:56-61; discussion 61-2

17. Hsieh TM, Cheng Tsai T, Liang JL, Che Lin C. Nonoperative management attempted for selective high grade blunt hepatosplenic trauma is a feasible strategy. World J Emerg Surg. 2014:25;9:51. doi: 10.1186/1749-7922-9-51 eCollection 2014

18. Ochsner MG. Factors of failure for nonoperative management of blunt liver and splenic injuries. World J Surg. 2001;25:1393-6

19. McIntyre LK, Schiff M, Jurkovich GJ. Failure of nonoperative management of splenic injuries: causes and consequences. Arch Surg. 2005;140:563-8; discussion $568-9$

20. Bala M, Edden Y, Mintz Y, et al. Blunt splenic trauma: predictors for successful non-operative management. Isr Med Assoc J. 2007;9:857-61.

http://dx.doi.org/10.17546/msd.15377

21.

Rodrigues CJ, Sacchetti JC, Rodrigues AJ Jr. Age-related changes in the elastic fiber network of the human splenic capsule. Lymphology. 1999;32:64-9.

22. Renzulli P, Gross T, Schnüriger B, et al. Management of blunt injuries to the spleen.Br J Surg. 2010;97:1696-703. doi: $10.1002 /$ bjs. 7203

23. Pal JD, Victorino GP. Defining the role of computed tomography in blunt abdominal trauma.Use in the hemodynamically stable patient with a depressed level of consciousness. Arch Surg. 2002;137:1029-33

24. Sosada K, Wiewióra M, Piecuch J. Literature review of non-operative management of patients with blunt splenic trauma: impact of splenic artery embolization.Wideochir Inne Tech Maloinwazyjne. 2014:9:309-14 doi: 10.5114/wiitm.2014.44251. Epub 2014 Jul 23.

25. Meguid AA, Bair HA, Howells GA, Bendick PJ, Kerr HH, Villalba MR. Prospective evaluation of criteria for the nonoperative management of blunt splenic trauma. Am Surg. 2003;69:238-42.

Berg $\mathrm{RJ}$, Inaba $\mathrm{K}$, Okoye $\mathrm{O}$, et al. The contemporary management of penetrating splenic trauma. Injury. 2014 Sep;45:1394-400. doi: 10.1016/j.injury.2014.04.025. Epub 2014 Apr 18

27. Schurr MJ, Fabian TC, Gavant M, et al. Management of blunt splenic trauma: computed tomographic contrast blush predicts failure of nonoperative management. J Trauma. 1995;39:507-12; discussion 512-3

28. Bee TK, Croce MA, Miller PR, Pritchard FE, Fabian TC. Failures of splenic nonoperative management: is the glass half empty or half full? J Trauma. 2001;50:230-6.

29. Malhotra AK, Latifi R, Fabian TC, et al. Multiplicity of solid organ injury: influence on management and outcomes after blunt abdominal trauma. J Trauma. 2003;54:925-9.

30. Demetriades D, Hadjizacharia P, Constantinou C, et al. Selective nonoperative management of penetrating abdominal solid organ injuries. Ann Surg. 2006;244: 6208 .

31. Beuran M, Gheju I, Venter MD, Marian RC, Smarandache R. Non-operative management of splenic trauma.Med Life. 2012 Feb 22;5(1):47-58. Epub 2012 Mar 5.

32. Pachter HL, Guth AA, Hofstetter SR, Spencer FC. Changing patterns in the management of splenic trauma: the impact of nonoperative management. Ann Surg. 1998;227:708-17.

Copyright (C) 2014 The Author(s); This is an open-access article distributed under the terms of the Creative Commons Attribution License (http://creativecommons.org/licenses/by/4.0), which permits unrestricted use, distribution, and reproduction in any medium, provided the original work is properly cited. All Rights reserved by international journal of Medical Science and Discovery.

Medical Science and Discovery, 2016;3(2): 60-4 